\title{
Simulation Study on Characteristic of Combustion and Emission of Super-high Pressure Common Rail Diesel Engine
}

\author{
Qi Liu ${ }^{1}$, Guangyao Ouyang ${ }^{1}$, Kun Yang ${ }^{1}$, Yupeng Sun ${ }^{2}$ \\ ${ }^{1}$ College Power Engineering, Naval University of engineering, Wuhan 430033, China \\ ${ }^{2}$ Dalian Navy area equipment maintenance supervisor room, Dalian 116041, China
}

Keywords: super-high pressure; diesel engine; combustion and emission; FIRE

\begin{abstract}
The super-high pressure common rail system was designed innovatively for improving the fuel atomization characteristic of high power diesel engine. The three-dimension combustion model of super-high pressure common rail system was constructed on the AVL Fire software platform. The numerical simulation of the fuel atomization and combustion process at standard load condition was completed. The results showed that the fuel injection law could become more flexible by regulating the super-high pressure common rail system; The whole heat release and power capability of super-high pressure common rail system is larger; The quantity of NOx, soot and fuel consumption rate of traditional pressure common rail system is higher; The super-high pressure injection shows more superiority and potential than tradition high pressure injection on combustion and emission characteristic.
\end{abstract}

\section{Introduction}

Diesel engine has several advantages such as its larger power scope, higher thermal efficiency and better reliability. It has become the main object of different vehicles and used in other fields widely. Since the 21st century, with the drying up of petroleum and deepening of environment pollution, diesel engine is facing the challenge of energy and environmental protection. The request to improve its characteristic of economy and emission has been very imminent. Studies in recent years show that the fuel injection pressure is becoming more and more high, and it can reach to 250 $\mathrm{MPa}$ on some diesel engines at present. From the tradition view, the pressure is called super high pressure when it is higher than 180MPa. Fuel injection based on super-high pressure can promote fuel droplets more refined, improve the quality of combustible mixed gas and shorten the ignition delay. The effect of combustion will be improved enormously and it must affect the overall performance of diesel engine. With the increase of engine power and speed, the injection pressure will gradually continue to rise[1].

In this dissertation, the author designed a simulation model of super-high common rail system. By regulating this system, the curve of fuel injection law can be change flexibly. A three-dimension combustion model of this system was constructed. The numerical simulation method is used to study the characteristic of adjustable fuel injection law, in-cylinder fuel atomization and combustion process. The calculation result lay the foundation for the research in combustion and emission based on super-high common rail system[2].

\section{Simulation model}

The Hydsim is fuel injection system simulation software belong to Workspace. It is based on the theory hydrodynamics and multi-body dynamics. The super-high common rail system simulation model is set up on Hydsim which is composed of high pressure pump module, pressure-amplified pump module, common-rail module and fuel injector module, as shown in figure 1. 


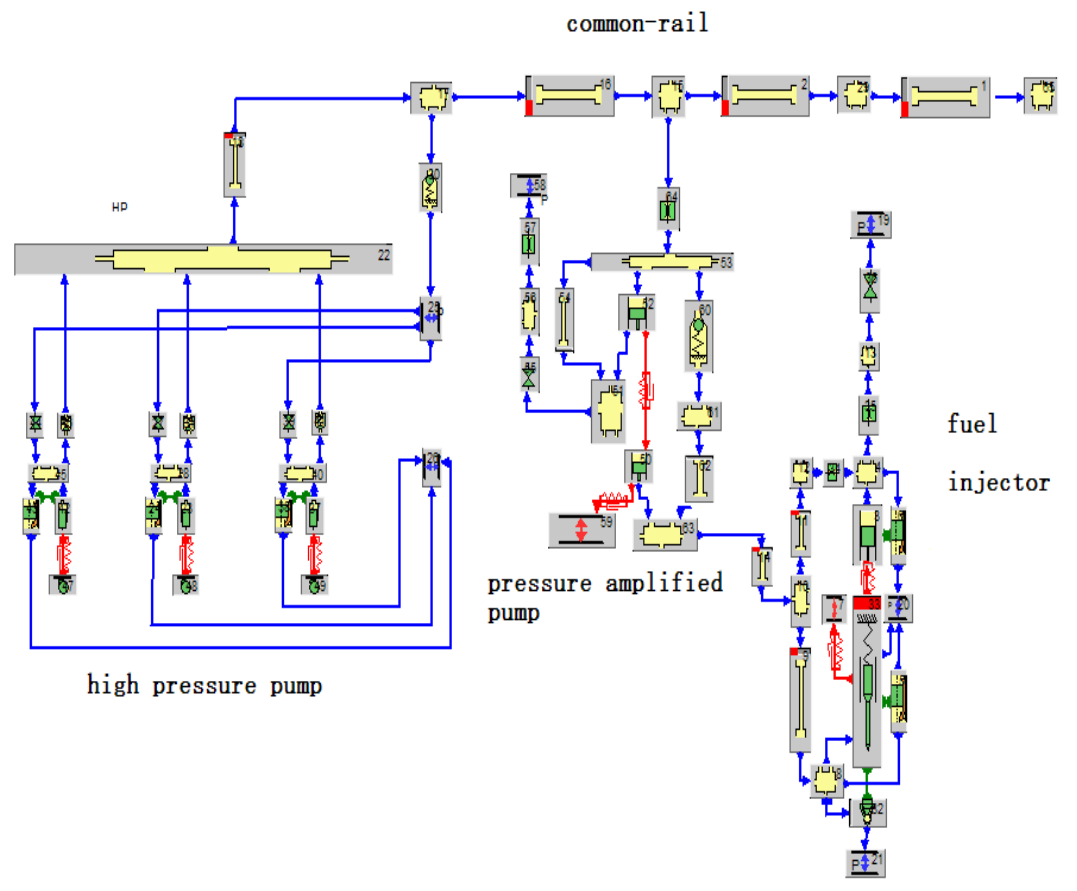

Fig.1 Simulation model of the super-high pressure common-rail system

The basic principle of super-high common rail system is: setting up the second stage electric control pressure amplifier pump between common-rail module and fuel injector module. The basic pressure of common-rail keeps at around $100 \mathrm{MPa}$. When fuel flows from common-rail to injector through the pressure amplifier pump, its pressure could be increased to $200 \mathrm{MPa}$ if necessary, then injects into cylinder. The basic pressure can satisfy the needs of fuel at low load. Super-high pressure can meet the needs of fuel at standard load. At the same time of load changes, we can control the opening and closing time of the two solenoid valves in pressure amplifier pump and fuel injector[3,4]. Thus different shapes of fuel injection law curves could be realized.

Tab.1 Parameters of simulation model

\begin{tabular}{|c|c|c|c|}
\hline module & parameter setting & module & parameter setting \\
\hline common rail pressure & $100 \mathrm{MPa}$ & $\begin{array}{c}\text { volume of control } \\
\text { chamber }\end{array}$ & $620 \mathrm{~mm}^{3}$ \\
\hline diameter of nozzle hole & $0.4 \mathrm{~mm}$ & moving mass of needle & $2.6 g$ \\
\hline length of nozzle hole & $0.9 \mathrm{~mm}$ & number of nozzle holes & 4 \\
\hline $\begin{array}{l}\text { volume of pressure } \\
\text { amplifier chamber }\end{array}$ & $320 \mathrm{~mm}^{3}$ & $\begin{array}{l}\text { moving mass of pressure } \\
\text { amplifier piston }\end{array}$ & $30 \mathrm{~g}$ \\
\hline $\begin{array}{c}\text { hydraulic diameter of } \\
\text { orifice }\end{array}$ & $0.2 \mathrm{~mm}$ & diameter of needle guide & $6.5 \mathrm{~mm}$ \\
\hline $\begin{array}{l}\text { moving mass of control } \\
\text { piston }\end{array}$ & $10.7 \mathrm{~g}$ & needle lift & $0.35 \mathrm{~mm}$ \\
\hline $\begin{array}{c}\text { volume of pressure } \\
\text { chamber }\end{array}$ & $170 \mathrm{~mm}^{3}$ & diameter of control piston & $7 \mathrm{~mm}$ \\
\hline
\end{tabular}


Tab.2 Time controlling of solenoid valves

\begin{tabular}{ccc}
\hline Time controlling & traditional pressure & super-high pressure \\
\hline Open time of injector(ms) & 2 & 2 \\
Close time of injector(ms) & 4 & 4.7 \\
basic pressure & 100 & 100 \\
open time of amplifier pump & 2 & 3.9 \\
close time of amplifier pump & 4 & 4.7 \\
amplifier pressure & 60 & 80 \\
\hline
\end{tabular}

Table 1 shows the basic parameters of super-high common rail system model. Table 2 shows the time controlling of solenoid valves in fuel injector and pressure amplifier pump. Assuming the opening and closing time of solenoid valves have no time-delay. We keep the basic pressure of common-rail and the amount of injecting fuel constant. After simulation calculation, different fuel injection laws can be obtained as shown in figure 2.

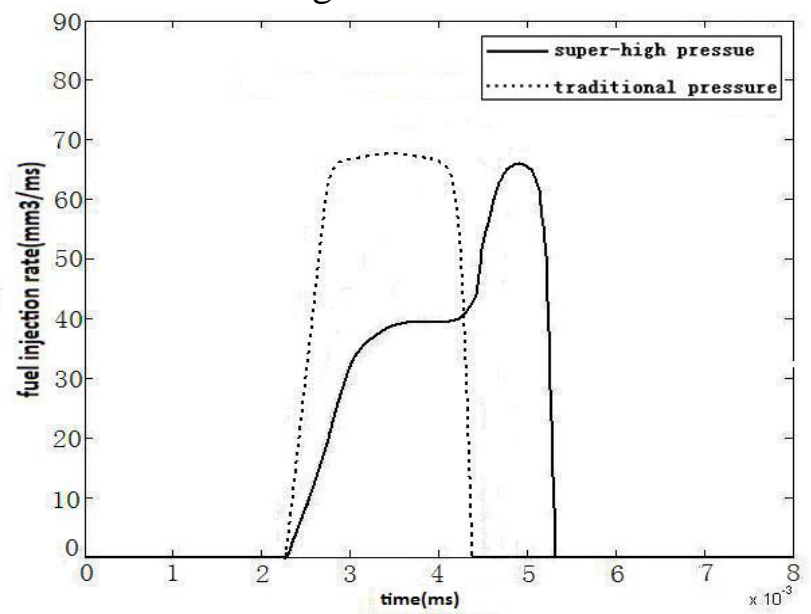

Fig.2 Adjustable fuel injection laws

It is shown that with the increase of interval between opening and closing time of solenoid valves, the fuel injection duration lasts longer, and the peak value of fuel injection rate declines substantially. At the very start, the fuel injection rate is low. With the upward movement of the piston, the injection rate becomes higher. The temperature and pressure conditions have been improved at this moment. So the curve of injection law is more suitable for fuel atomization.
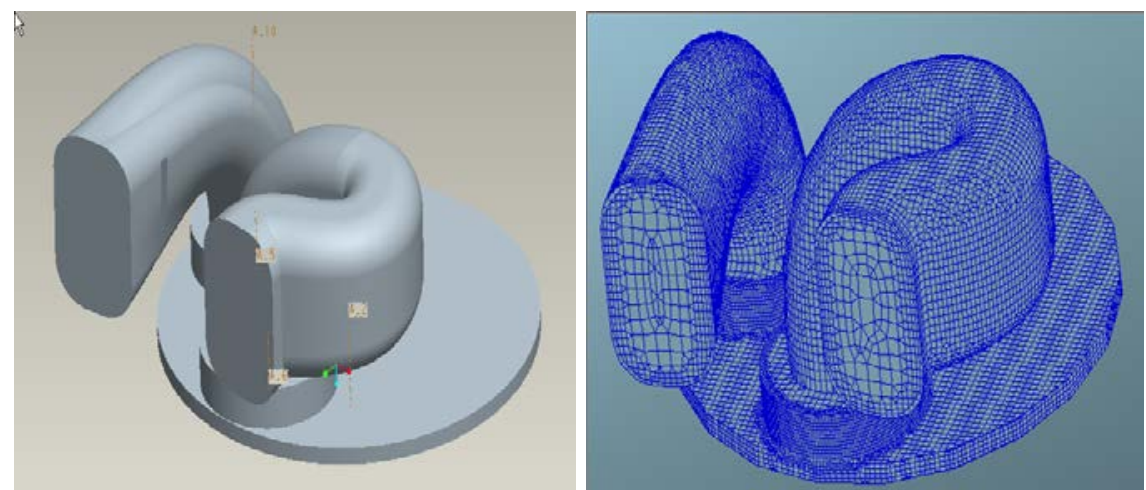

Fig.3 Geometric model and dimensional grid of combustion model

The three-dimension combustion model includes air intake ports, valves and combustion chamber. It is meshed by using AVL FIRE software, as shown in figure 3. The number of three-dimension grid is about $1.5 \mathrm{million}$. Defining the crank angle when the piston is in TDC position as $360^{\circ}$. The intake valve opening and closing time is $315^{\circ} \mathrm{CA}$ and $580^{\circ} \mathrm{CA}$. 
The calculation range is $360^{\circ} \mathrm{CA}-850^{\circ} \mathrm{CA}$. The turbulence model chooses the $k-\varepsilon-f$ model which is more stable. The differencing scheme of momentum equation chooses the MINIMOD Relaxed model. The fuel atomization model chooses the WAVE discrete model. The evaporation model chooses the DUKOWICZ model. The combustion model choose the ECFM-3Z model. The load of diesel engine choose standard load. NOx model choose Advanced NOx Model. Soot model choose Advanced Soot Model. Assuming the in-cylinder air is uniform and there are the same temperature and pressure when calculating[5]. The calculating step of fuel spraying stage use $0.4^{\circ}$. Increasing the calculating step to $1^{\circ}$ when combustion process begins.

\section{Results and discussions}

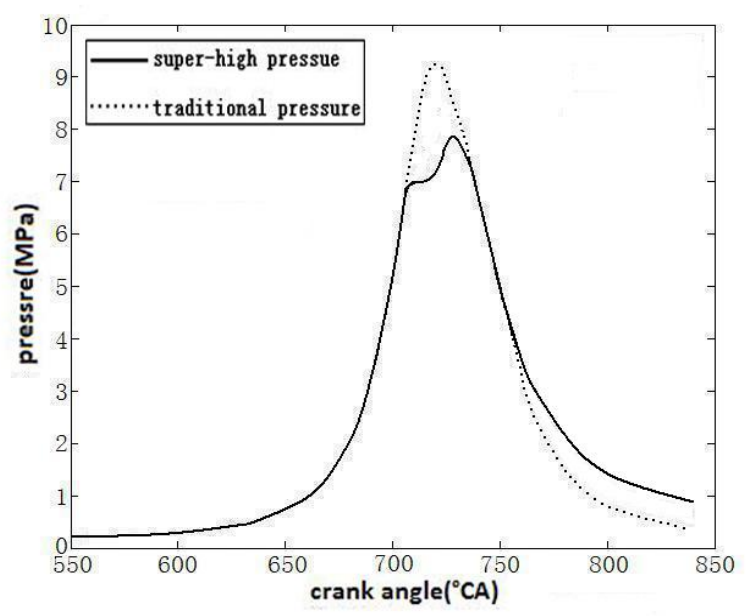

(a)

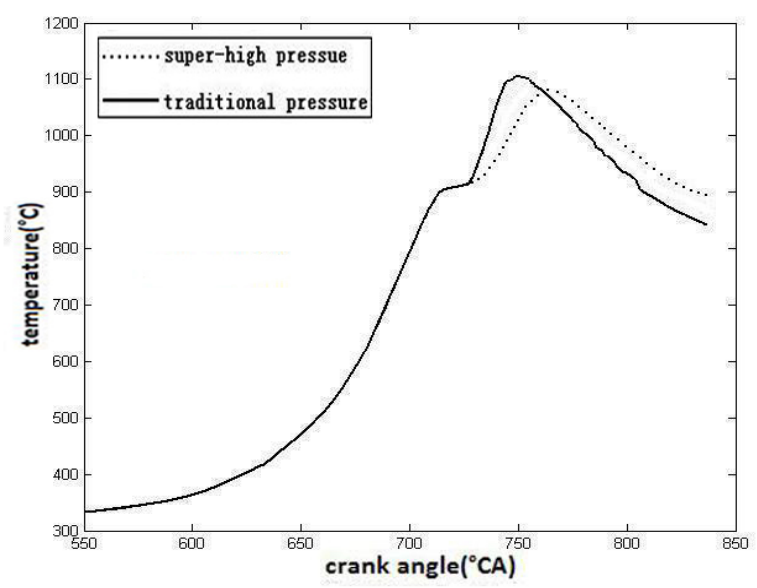

(b)

Fig.4 Contrast of combustion and emission performance

Figure 4 shows the contrast of combustion and emission performance. With the injecting pressure increases and the shape of fuel injection law changes, the peak value of pressure and temperature declined substantially. The time of peak value of pressure and temperature have also been delayed. The whole heat release of super-high pressure is larger and so does its power capability. That is because the pressure of traditional fuel injection law always stay the same, it runs up to the peak value as soon as fuel injecting. Too much fuel inject into cylinder in ignition delay period. The pressure and temperature in-cylinder are not high enough. So fuel droplets can not be atomized adequately and the mixed gas is not uniform. It leads to imperfect combustion process happening[69]. 


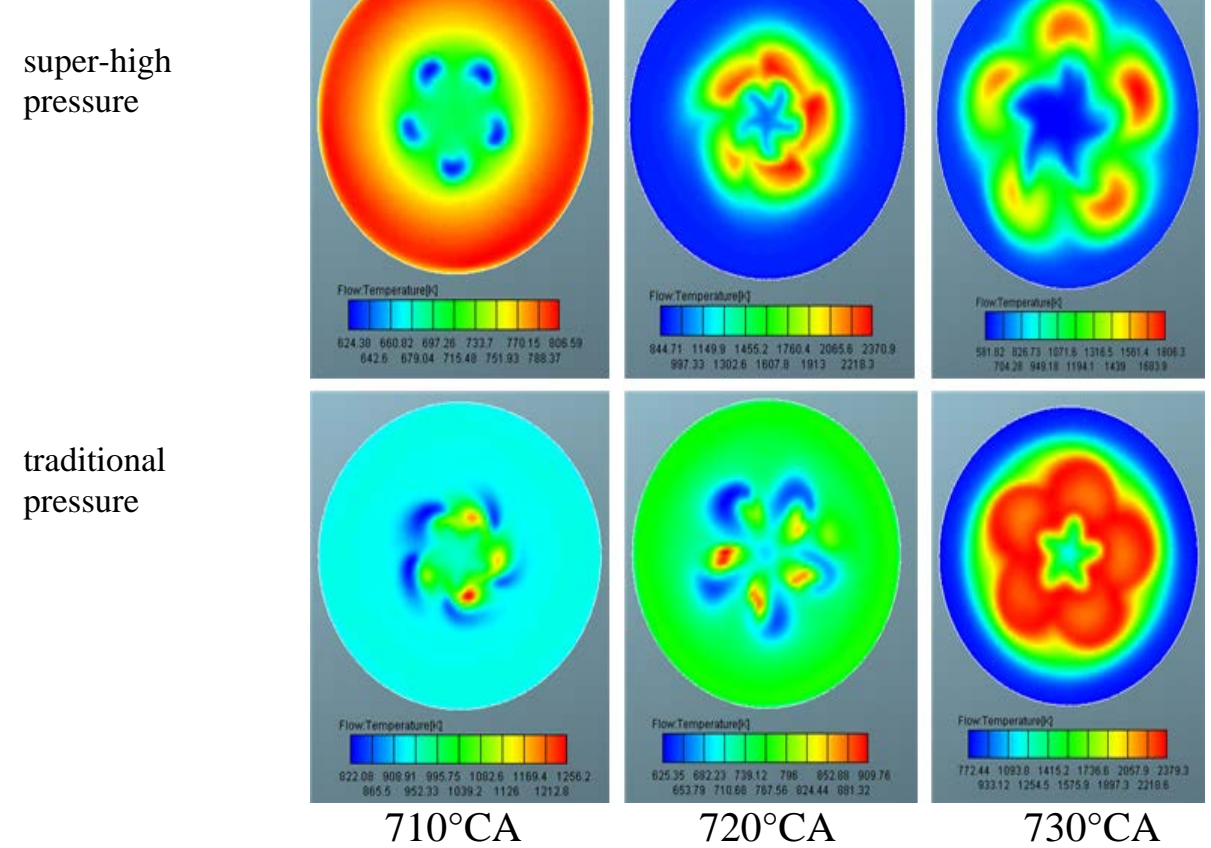

Fig. 5 Contrast of temperature field

Figure 5 shows the three-dimensional in-cylinder temperature fields changes with time. At $710^{\circ} \mathrm{CA}$, the overlap region of fuel under traditional pressure is a little larger and concentrated near the nozzles. The oil beams under super-high pressure are relatively decentralized. As time goes on, at $730^{\circ} \mathrm{CA}$, there are obvious high temperature area around oil beams when the injecting pressure is super-high pressure. It illustrates that fuel have already began to burn adequately. However, we can see the distribution of oil beams under traditional pressure clearly. There are only a few high temperature points around the oil beams. Lower pressure and traditional fuel injection law are not good to combustion process obviously[10].

Tab.3 Contrast of emission results

\begin{tabular}{ccc}
\hline emission results & $\begin{array}{c}\text { super-high } \\
\text { pressure }\end{array}$ & $\begin{array}{c}\text { traditional } \\
\text { pressure }\end{array}$ \\
\hline exhaust & 435 & 450 \\
temperature $\left({ }^{\circ} \mathrm{C}\right)$ & & \\
noise $(\mathrm{dB})$ & 95 & 97 \\
NOx $(\mathrm{ppm})$ & 712 & 730 \\
soot $(\%)$ & 4.5 & 7.0 \\
fuel consumption & 195.8 & 203.6 \\
rate $(\mathrm{g} / \mathrm{kW} \cdot \mathrm{h})$ & & \\
\hline
\end{tabular}

Table 3 shows the emission results of super-high pressure common rail system and traditional pressure common rail system. The quantity of NOx and soot under super-high pressure is lower than the emissions under traditional pressure. The reason for the result is because that in-cylinder fuel has better atomization effect under super-high pressure. The overall combustion is more uniform. Concentration of local oxygen enriched zone is low, it leads to reduce the quantity of NOx and soot. The Uniform mixed gas is very beneficial to improve combustion efficiency. So the superhigh pressure common rail system has a good economical efficiency, its fuel consumption rate is lower too. 


\section{Conclusions}

1.The adjustable fuel injection law could be realized by controlling the opening and closing time of the two solenoid valves in pressure amplifier pump and fuel injector. The curve of fuel injection law becomes more flexible.

2.The peak value of pressure and temperature of super-high pressure common rail system is lower. Its whole heat release is larger and so does its power capability.

3.The combustion process of super-high pressure common rail system is more sufficient. Its quantity of NOx, soot and fuel consumption rate is lower. The super-high pressure injection shows more superiority and potential than tradition high pressure injection on combustion and emission characteristic.

\section{Acknowledgements}

The research work was supported by National Natural Science Foundation of China under Grant No. 51379212.

\section{References}

[1] Ouyang Guang-Yao, Chang Han-Bao \& Yang Yan-Tao. TBD620 series diesel engine[M]. Beijing: HaiChao publish, 2006:1-2.

[2] Shao Li-Min. Optimum Study on Injection System Parameters of High Pressure Common Rail Diesel Engine [D]. Wuhan: Naval University of Engineering, 2010.

[3] Chen Hai-Long, Ouyang Guang-Yao \& Zhang Jing-Qiu. Research on new electric control pressure amplifier applied to augment high-pressure common-rail system[J].Chinese Internal Combustion Engine Engineering, 2011, 32(5):44-48.

[4] Qin Chao-Ju, Liu Jian-Xin \& Du Hui-Yong, et al. Present situation and development perspective of high-pressure common rail injection systems with in Bosch Company[J]. Tractor and Farm Transporter, 2006, 33(2):3-6.

[5] AVL-Fire Reference Manual, Version8.5 [EB/OL]. http: //www. avl. com, 2006-12.

[6] Chen Yong-Xian, Yu Wen-Bin \& Guo Shu-Man, et al. Effect of several combustion control parameters on emissions and efficiency of a diesel engine under low load[J]. Transactions of Csice, 2011, 29(3):193-199.

[7] Lin Xue-Dong, Li De-Gang \& Tian Wei. Air-fuel mixture formation and combustion process of a high-speed direct-injection diesel engine with high pressure injection[J]. Journal of Jilin University (Engineering and Technology Edition), 2009, 39(6):1146-1151.

[8] Serres Pereira J, Romunde Z, Aleiferis P G, et al. Cavitation, primary break-up and flash boiling of gasoline, isooctane and pentane with a real size optical direct injection nozzle[J]. Fuel, 2010, 89(3):2592-2607.

[9] Park S H, Suh H K \& Lee C S.Nozzle flow and atomization characteristics of ethanol blended biodiesel fuel[J]. Renewable Energy, 2010, 35(4):144-150.

[10]O'Rourke P J, Bracco F V. Modeling of Drop Interactions in Thick Sprays and Comparisons with Experiments[J]. Proc.I.Mech.E, 1980(9): 101-116. 